\title{
Modelling, Simulation and Sensitivity Analysis of a Fatty Acid Methyl Ester Reactive Distillation Process Using Aspen Plus
}

\author{
Refiner Chikere ANENE ${ }^{1, a}$ and Abdulwahab GIWA ${ }^{2, b^{*}}$ \\ ${ }^{1}$ Chemical and Petroleum Engineering Department, College of Engineering, Afe Babalola \\ University, KM. 8.5, Afe Babalola Way, Ado-Ekiti, Ekiti State, Nigeria \\ ${ }^{2}$ Chemical and Petroleum Engineering Department, College of Engineering, Afe Babalola \\ University, KM. 8.5, Afe Babalola Way, Ado-Ekiti, Ekiti State, Nigeria \\ arefineranene@gmail.com, bagiwa@abuad.edu.ng
}

Keywords: Fatty acid methyl ester (FAME), modelling, simulation, sensitivity analysis, Aspen Plus, reactive distillation

\begin{abstract}
Reactive distillation, being an intensified process of combining reaction and distillation in a single vessel, is an ongoing research. This work considered the use of this novel process to investigate how the purity of a fatty acid methyl ester (oleic acid methyl ester - methyl oleate), which is an alternative fuel that has a potential economic bedrock, vary with variations in reflux ratio and reboiler duty with the aid of Aspen Plus model of the process. The column employed in developing the model of the process was a RadFrac type having 29 stages, which was divided into five sections, namely condenser (top), rectifying, reaction, stripping and reboiler (bottom) sections. After the development, the model was simulated using UNIversal QUAsiChemical model (UNIQUAC) base method. In order to investigate the sensitivity of the system, reflux ratio and reboiler duty were varied from 2.0-5.5 and 1350-1800 W, respectively. The results obtained from the steady-state simulation of the process revealed that the developed Aspen Plus model of the system was table because it was able to converge when simulated. Furthermore, it was discovered from the sensitivity analysis carried out that a methyl oleate having a mole fraction of approximately 0.7627 could be obtained from the process when the reflux ratio and the reboiler duty were 2.0 and $1800 \mathrm{~W}$ respectively. Also, it was observed that the mole fraction of methyl oleate was sensitive to both reflux ratio and reboiler duty because the variations in them (reflux ratio and reboiler duty) resulted in corresponding variation in the methyl oleate mole fraction obtained from the system.
\end{abstract}

\section{Nomenclature}

A, B, C and D Equilibrium reaction constants

b.p. $\quad$ Boiling point $\left({ }^{\circ} \mathrm{C}\right)$

FAME Fatty acid methyl ester

FAMERDP Fatty acid methyl ester reactive distillation process

METHYLOL Methyl oleate

MOLE RR Reflux ratio

OLEICAC Oleic acid

QN Reboiler duty (W)

RD Reactive Distillation

RDC Reactive Distillation Column

RR Reflux ratio

UNIQUAC UNIversal QUAsiChemical model

\section{Introduction}

Generally, a model intended for a simulation study can be a type developed with the help of simulation software. Mathematical model classifications include deterministic (input and output variables are fixed values) or stochastic (at least one of the input or output variables is 
probabilistic), static (time is not taken into account) or dynamic (time-varying interactions among variables are taken into account). Development of a model is carried out through modelling while the solution is often referred to as simulation [1].

Modelling and simulation may enhance the insight, clarify dependencies, predict behaviour, explore the system boundaries; however, they will not reveal knowledge that is unknown. A model is a reflection of the experiments that have been performed and a good trade-off between realism and simplicity [2]. Modelling and simulation can be used to foretell and predict the future of a system with the use of computers. In addition, the desire to understand what happens in systems in which measurements are impossible or impractical has brought about the development of many computational models [3].

To further increase the thoroughness of the investigation, a computer-simulated model is subjected to different conditions of process parameters. The response and reaction of the model to these parameters reveal parameters upon/to which the model is dependent/independent, responsive/unresponsive or sensitive/insensitive. This phenomenon is what is referred to as sensitivity analysis.

Sensitivity analysis is defined as the study of how uncertainty in the output of a model can be attributed to different sources of uncertainty in the model input(s). It is a technique that involves investigating how different values of an independent variable will impact a particular dependent variable under a given set of assumptions. This technique is used within specific boundaries that will depend on one or more input variables [4], and it is now being applied in the area of energy for efficiency, especially in the production of fatty acid methyl ester (FAME).

Fatty acid methyl ester (FAME) is a substance that is made from virgin or used vegetable oils (both edible and non-edible) and animal fats. It can be used to operate compression ignition engines like petro-diesel, and it can be blended in any ratio with petroleum diesel fuels. It can also be stored just like the petroleum diesel fuel. The physical characteristics of fatty acid esters are closer to those of fossil diesel fuels than pure vegetable oils, but their properties depend on the type of vegetable oils used for their production. A mixture of different fatty acid methyl esters is commonly referred to as biodiesel, which is a renewable alternative fuel. Apart from FAME having physical properties that are similar to those of conventional diesel, it is non-toxic and biodegradable [5]. Considering the chemistry of its production, FAME can be manufactured in a continuous process using reactive distillation process [6].

Reactive distillation (RD) is the process in which chemical reaction and separation are carried out simultaneously within a fractional distillation apparatus. It may be advantageous for liquid-phase reaction systems when the reaction must be carried out with a large excess of one or more of the reactants, when a reaction can be driven to completion by removal of one or more of the products as they are formed, or when the product recovery or by-product recycle scheme is complicated or made infeasible by azeotrope formation [5]. The chemical reaction of the process usually takes place in liquid phase or at the surface of a solid catalyst in contact with the liquid phase. It is a so-called hybrid process in the sense that it merges two different unit operations in a single piece of equipment [7-10], namely reaction and separation (distillation). A lot of benefits are associated with this process, especially for those reactions occurring at temperatures and pressures suitable for the distillation of the reaction components [11-21]. Reactive distillation combines the benefits of equilibrium reaction with distillation to achieve a substantial progress in promoting reaction conversion as a result of constant recycling of unconverted materials and removal of products. Also, reduction of capital and operating costs as a result of the reduction of number of equipment units of the plant $[18,21-23]$ is another benefit of the process. Moreover, basically, the combination of reaction and distillation has several advantages which include increase of reaction conversion by simultaneous reaction and separation of products, suppression of side reaction(s) and utilization of heat evolved from an exothermic reaction for mass transfer operation. These synergistic effects of the process result in low capital investment, low energy cost and high product yields $[21,24]$. 
Generally, reactive distillation can be used with a wide variety of reactions including acetylation, aldol condensation, alkylation, amination, dehydration, esterification, etherification, hydrolysis, isomerization, oligomerization, and trans-esterification [25] and so on. With regards to fatty acid methyl ester production (which can be carried out using esterification or transesterification reaction) and purification, and more specifically to large-scale production of biodiesel, it would appear that reactive distillation could provide an efficient and integrated approach to obtain the desired fatty acid esters in high purity, though this may depend on some factors. In order to investigate how some of these factors affect FAME production, in the absence of a physical plant for the production, a process simulator can be employed, and one of those process simulators is Aspen (Advanced System for Process Engineering) Plus [5].

Aspen Plus offers a complete integrated solution to chemical process industries. This sophisticated software package can be used in almost every aspect of process engineering from design stage to cost and profitability analysis. It has a built-in model library for distillation columns, separators, heat exchangers, reactors, etc. With Aspen Plus, specifications such as flow sheet configuration, operating conditions and feed compositions can interactively be changed in order to run new cases and analyse process alternatives. The simulator allows a wide range of tasks such as estimating and regressing physical properties, generating custom graphical and tabular output results, fitting plant data to simulation models, optimizing processes, and interfacing results to spreadsheets to be performed. Aspen PLUS is a process simulation tool used industrially and academically. It is the market-leading chemical process optimization software used by the bulk, fine, specialty, and biochemical industries, as well as the polymer industry for design, operation, and optimization of safe and profitable manufacturing facilities. It offers a lot of benefits which include supporting full range of process industries, continuously improving chemical process designs with Activated Analysis, expanding modelling to include solids, comparing simulation and plant data in real time, extending functionality with layered applications, and using highest fidelity engineering platform [5].

The reactive distillation concept appears to have been first pronounced by Backhaus, who, starting in 1921, obtained a series of patents for esterification reaction in a distillation column. This concept of continuous and simultaneous chemical reaction and distillation in a single vessel was verified experimentally by Leyes and Othmer [5] for the esterification of acetic acid with an excess of n-butanol in the presence of sulphuric acid catalyst to produce butyl acetate and water. Since then, many researchers have tried to put more efforts in understanding the phenomena of this process with the aid of process simulators and/or pilot plants. Carrera-Rodríguez et al. [26] presented a short method for the design of a reactive distillation column using the method of distillation lines and tray-by-tray calculations. The method was easy to implement and provided a quick pre-design (providing operating parameters as a starting point) for a rigorous design method as opposed to the preliminary trial and error method to obtain operating parameters. The synthesis of MTBE with the presence of inert was used as a case of study to show the effectiveness of the proposed method that estimated the reflux ratio, the number of stages, and feed tray. This strategy showed a significant agreement with those obtained using Aspen Plus. Agarwal et al. [27] simulated and carried out sensitivity analysis on biodiesel production in a reactive distillation column making comparative analysis between results obtained from MATLAB and ChemCAD. The sensitivity analysis showed that yield of ester increased with methanol to oil ratio and number of stages, and decreased with flow rate. Road and Patil [28] worked on mathematical modelling and simulation of reactive distillation column using MATLAB and Aspen Plus. An equilibrium model of acetic acid with iso-amyl alcohol in a reactive distillation column of 27 stages (reboiler and condenser included) was employed. The simulations were based on the equilibrium-stage approach and, for comparison, a rate-based model was also used. In the work, the equilibrium model for synthesis of iso-amyl acetate was developed. The simulation studies were performed in Aspen Plus and MATLAB. Some published experimental data on phase equilibrium and reaction studies were used to verify the model predictions, and the results were found to be close to each other. Lone and Ahmad [29] carried out research on modelling and simulation of ethyl acetate reactive distillation 
column using RADFRAC model of Aspen Plus. They reported that the model showed satisfactory results and was especially suitable for the complexity of the selected process. Nwambuonwo and Giwa [30] used Aspen HYSYS to model, simulate and optimize a reactive distillation process used for the production of palmitic acid methyl ester. The model was successfully simulated and optimized using Aspen HYSYS after the developed model was able to converge when simulated at steady state. Datta and Patle [31] carried out sensitivity analysis of a heterogeneous reactive distillation (RD) process using Aspen PLUS for the production of methyl acetate using the esterification reaction of methanol and acetic acid. In the simulation, RADFRAC model was chosen to take care of the complexities arising due to simultaneous reaction and separation in a single unit. UNIQUAC property method was selected in the simulator for equilibrium calculations. The steady state results obtained from the work were validated with the experimental ones reported by Popken et al. [32]. Giwa and Giwa [33] investigated the effects of reflux ratio and reboiler duty on the operation of a reaction integrated distillation process used for the production of stearic acid methyl ester (SAME) that was obtained from the esterification reaction between stearic acid and methanol with the aid of Aspen Plus. Giwa and Giwa [34] investigated the effects of volumetric feed ratio of stearic acid and methanol on the purity of the stearic acid methyl ester (SAME) obtained from a reactive distillation process accomplished through an esterification reaction. The investigation was carried out by developing a model of the process with the aid of Aspen Plus using RadFrac column having 32 stages including the condenser and the reboiler.

Based on the review of literature carried out, to the best of our knowledge, work carried out on sensitivity analysis of a reactive distillation process for FAME, especially for oleic acid methyl ester, production is scarce. Therefore, it is aimed in this research work to investigate the behaviour of a model of a reactive distillation process developed with the aid of Aspen Plus that was used for the production of oleic acid methyl ester (methyl oleate) when subjected to different values of reflux ratio and reboiler duty.

\section{Methodology}

\section{Procedures for Model Development and Simulation}

Having chosen oleic acid as the reacting acid, methanol as the alcohol and methyl oleate as the desired product of the process, the esterification reaction involved in the reactive distillation process was as given in Equation (1).

$$
\mathrm{C}_{18} \mathrm{H}_{34} \mathrm{O}_{2}+\mathrm{CH}_{3} \mathrm{OH} \leftrightarrow \mathrm{C}_{19} \mathrm{H}_{36} \mathrm{O}_{2}+\mathrm{H}_{2} \mathrm{O}
$$

The Aspen Plus [35] model of the process was developed in Aspen Plus environment through the steps described below:

1. Component Selection: Components (reactants and products) for the reaction were selected from the existing database of Aspen Plus, and they were:

- oleic acid,

- methanol,

- methyl oleate, and

- water.

2. Base Method Selection: The base method selected in this work was UNIQUAC. This was chosen to be so based on the information obtained from the literature and a test run carried out where only the base methods were varied.

3. Main Flowsheet Development: The model structure was obtained from the Model Palette where FRACT 1 was selected from the RadFrac columns and material streams were used to pass the components into the equipment. The more volatile reactant, methanol (b.p. = $64.7^{\circ} \mathrm{C}$ ) was fed through a lower feed stream while the less volatile one, oleic acid (b.p. $=$ 
$359.85^{\circ} \mathrm{C}$ ) was passed via an upper feed stage. Following suit, the more volatile product, water (b.p. $=100{ }^{\circ} \mathrm{C}$ ) was collected with the top product stream while the less volatile product, methyl oleate (b.p. $=343.85^{\circ} \mathrm{C}$ ) was collected at the bottom section of the column. The flowsheet for the process was as shown in Figure 1, which was developed using the parameters given below:

- Total condenser

- Kettle reboiler

- Equilibrium reaction type

- 29 Stages of 5 sections.

(a) Condenser section: Stage 1

(b) Rectifying section: Stages 2-10

(c) Reaction section: Stages 11-19

(d) Stripping section: Stages 20-28

(e) Reboiler section: Stage 29

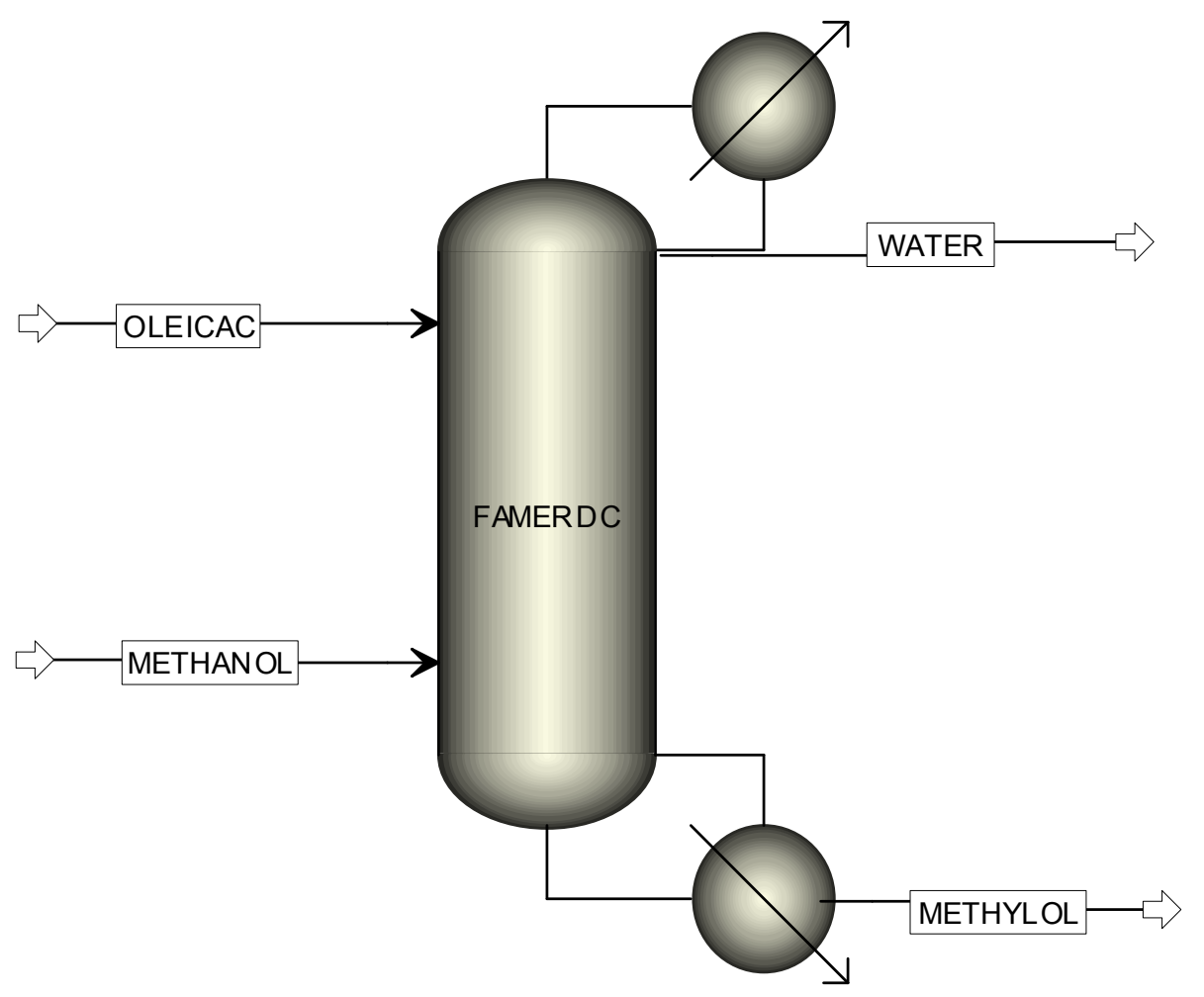

Figure 1. Aspen Plus flowsheet for the production of methyl oleate

4. Specifications for Reactant Streams: At a temperature and pressure of $25{ }^{\circ} \mathrm{C}$ and 1 bar respectively, each of the reactant compositions was set to mole-fraction, and their volumetric flow rate was also set to be $0.03 \mathrm{~L} / \mathrm{min}$. Oleic acid was made to enter the column at stage 11 while methanol was fed at stage 19.

5. Creating Reactions: A new reaction with its stoichiometry was named, and it was of the reactive distillation type. Reaction specifications were made for the block for reaction and reboiler sections.

6. Equilibrium Specifications: Equilibrium basis was set to molarity and the equilibrium constant was computed from a built-in expression. The equation was a function of temperature, and the values of its coefficients A, B, C and D were specified appropriately. 
7. Equipment Reaction Specifications: The reaction stage was specified for start and ending stages of 11 and 19 respectively as well as the reboiler.

8. Setup of Report Option: The fraction basis of the streams was set to mole basis.

\section{Sensitivity Analysis}

Sensitivity analysis of this work was carried out using the Model Analysis Tool of Aspen Plus by employing two (2) block variables: MOLE RR (reflux ratio) and QN (reboiler duty) as the input variables, and the output variable was chosen to be the mole fraction of methyl oleate obtained from the bottom section of the column. The range of the values used for the input variables as well as their increments were as given in Table 1.

Table 1. Ranges and increments of the input variables used

\begin{tabular}{lccc}
\hline Variable & Lower limit & Upper limit & Increment \\
\hline Reflux ratio & 2 & 5 & 0.5 \\
Reboiler duty $(\mathrm{W})$ & 1400 & 1800 & 5 \\
\hline
\end{tabular}

\section{Results and Discussion}

\section{Steady-State Results}

The results obtained from the steady-state simulation, which was carried out before proceeding to the sensitivity analysis, of the developed Aspen Plus model of the reactive distillation process for methyl oleate production are given in Figures $2-4$ respectively for the temperature, the mole fraction and the mass fraction profiles.

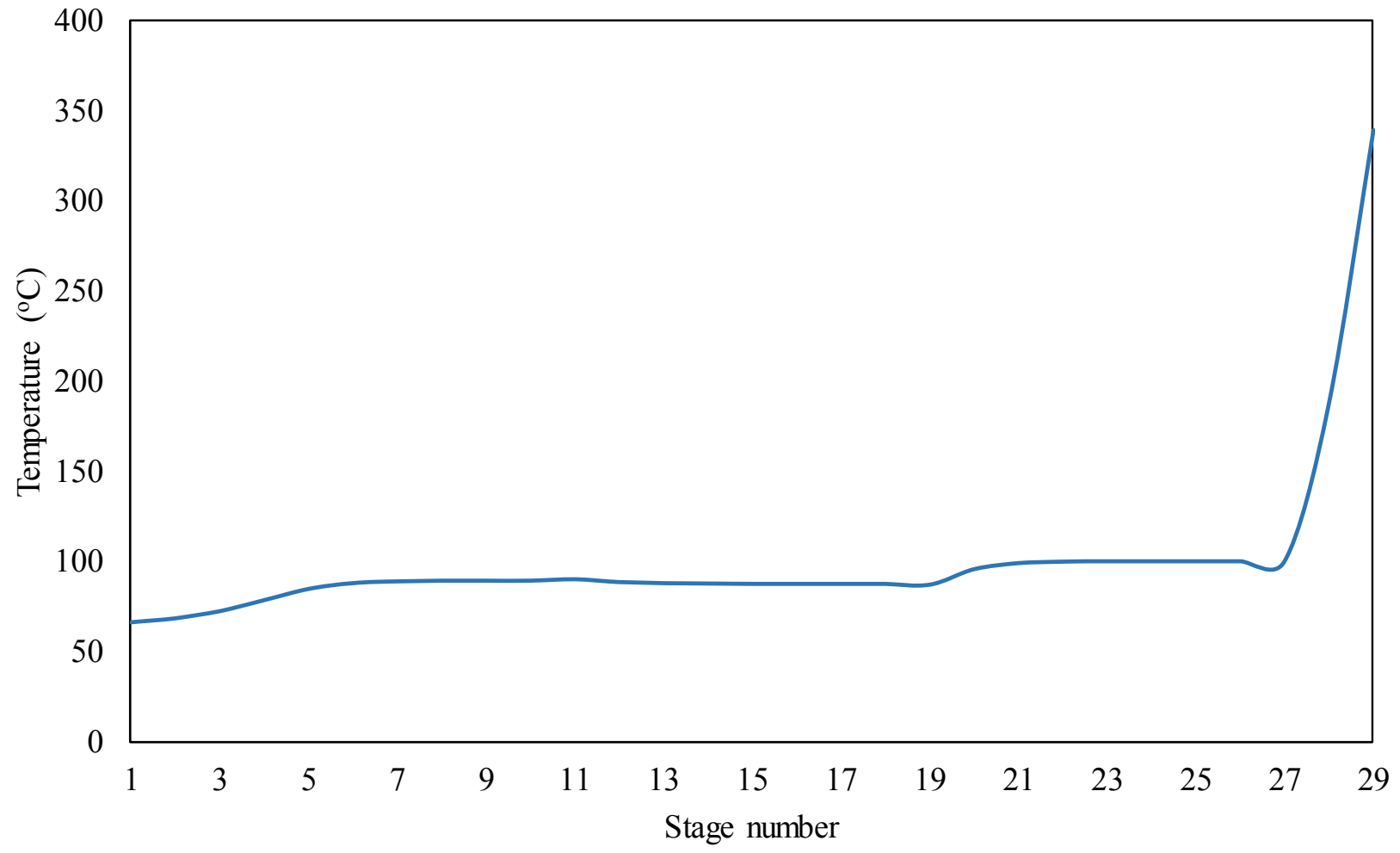

Figure 2. Temperature profile

Shown in Figure 2 is the temperature profile of the reactive distillation column. It can be observed from the figure that the temperature within each of the rectifying section, the reaction section and the stripping section was almost constant with their corresponding values. This was found to be an indication that the phenomenon occurring within each section of the column was uniform. Furthermore, as can also be seen from the figure, the lowest and the highest temperatures of the process were found to exist at the condenser and the reboiler sections, respectively. 


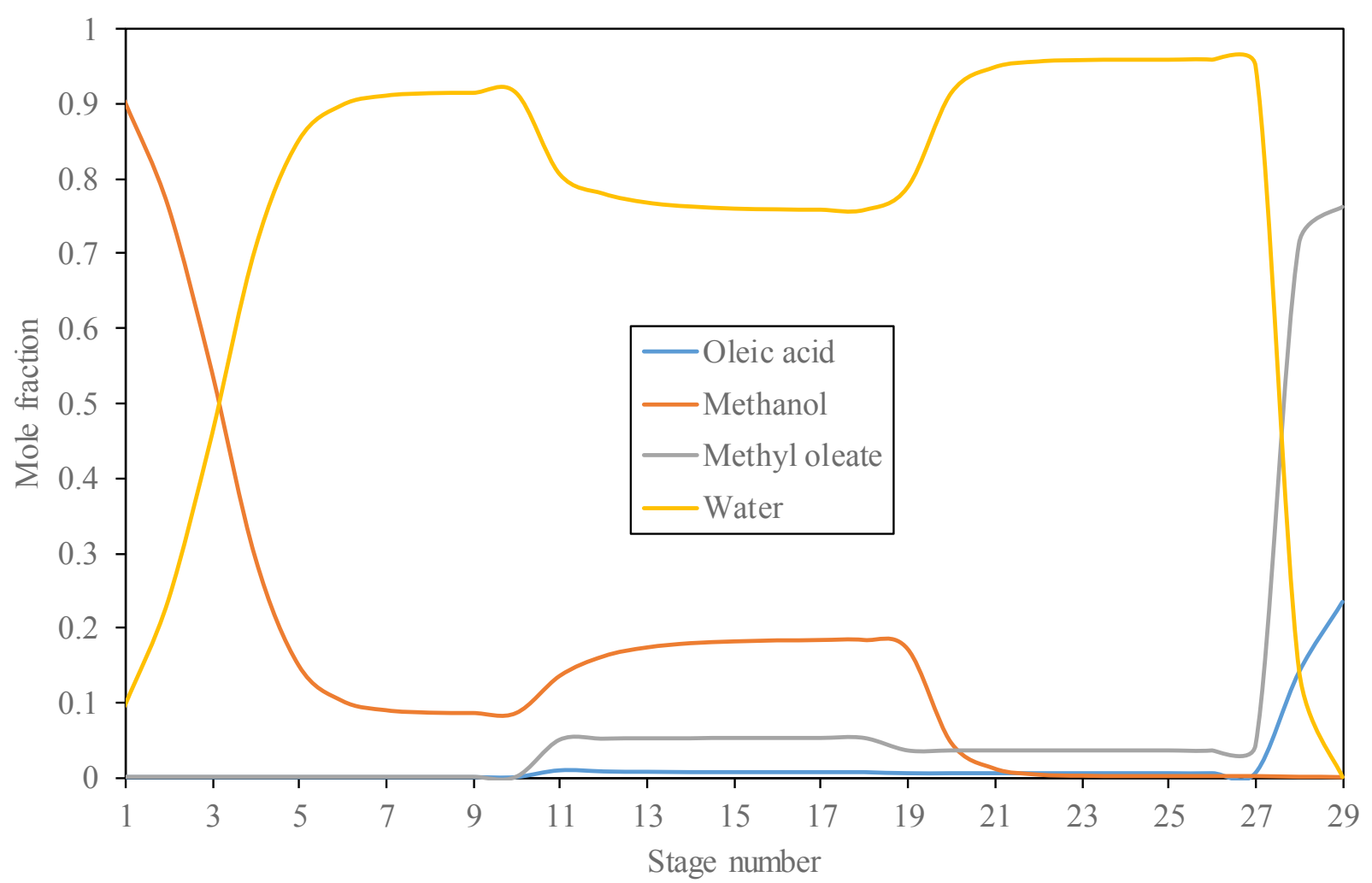

Figure 3. Mole fraction profiles of the process components

Figure 3 shows the liquid molar composition profile of the four components - acid: oleic acid, alcohol: methanol, ester: methyl oleate and by-product: water - involved in the process. Considering the almost " $m$ " and the near " $w$ " shapes of water and methanol plots respectively, it was discovered that the formation of water was proportional to the dissociation of methanol. Furthermore, at the bottom section of the column, the ester and unreacted oleic acid were found to be present in significant amounts while in the reaction zone, the dominant components were water and methanol. Also observed from the figure was that oleic acid was present in negligible amount in the condenser and rectifying sections because it was fed into the system at the $11^{\text {th }}$ stage where the reaction was taking place and, as a result of its being a heavy reactant, it was flowing downward the column where it was reacting and the unreacted one collected at the reboiler section where it had its highest mole fraction within the column. Moreover, methanol was observed to be absent at the stripping section because it was fed into the column at the $19^{\text {th }}$ stage and reacted with oleic acid uniformly, declined moderately and then built up towards its peak at the rectifying section and, thereafter, collected together with the by-product at the top section. Observing the plot of the desired product of the process, which was methyl oleate, it was discovered that it had the highest and the lowest mole fractions at the bottom and the top sections respectively. Based on the figure, methyl oleate was gradually formed in the reaction section and passed through the stripping section to the bottom section where it was the main constituent and collected as the main product. For the by-product of the process (water), its profile was found to be almost concave in nature, and it had its highest and lowest mole fractions at the top and the stripping sections of the column, respectively. Water was found to be the main component in the rectifying section before it was collected at the section of the column. 


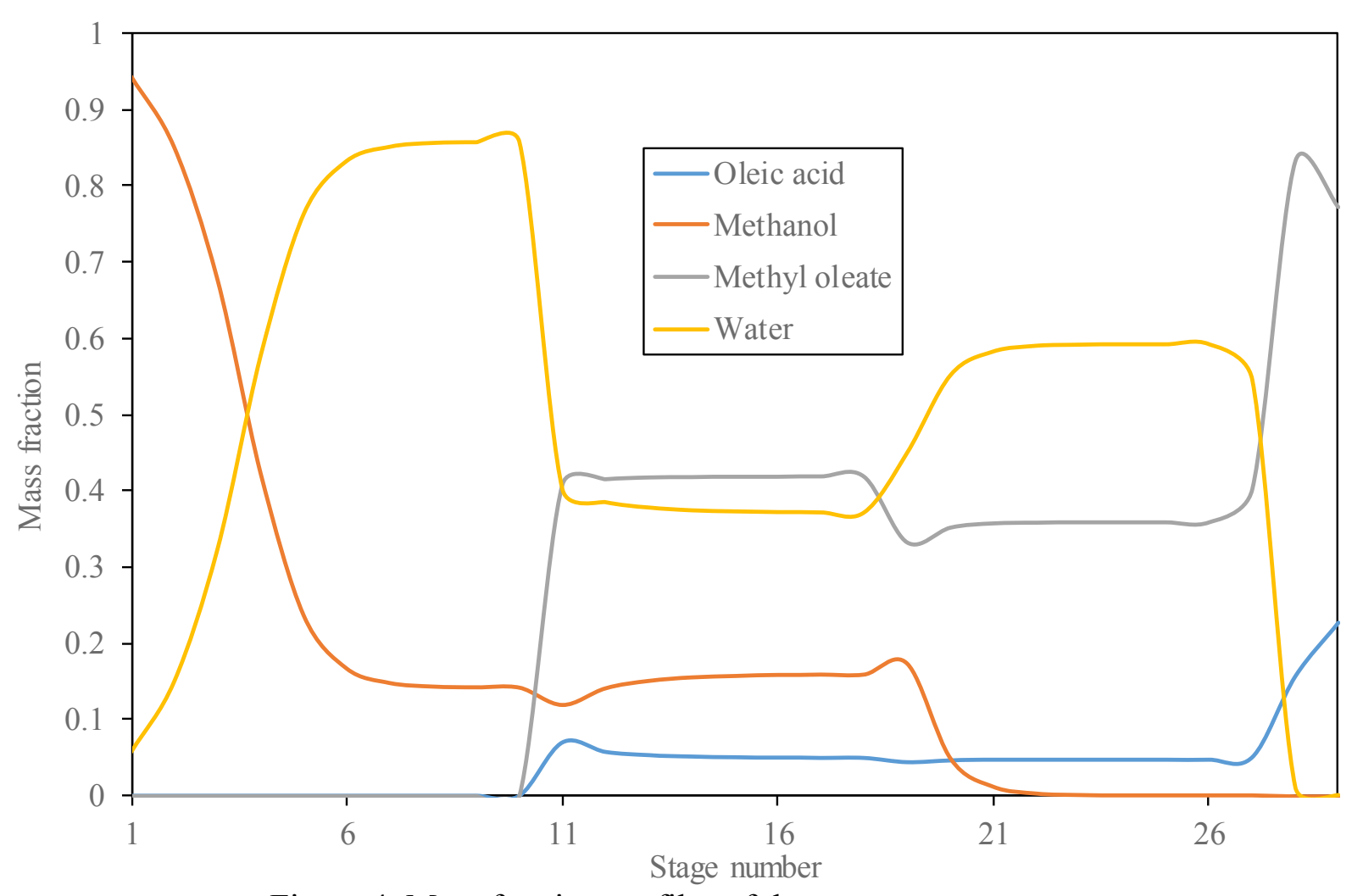

Figure 4. Mass fraction profiles of the process components

Given in Figure 4 are the mass composition profiles of oleic acid, methanol, methyl oleate and water that were the components of this process. From the observation made based on the plots shown in the figure, the mass composition of methyl oleate, the desired product, was found to increase with increasing stage number from top downward while that of methanol, a reactant, was found to decrease. The trends of the profiles of the components were found to be similar to those obtained in the case of the molar composition profiles of the components present within the column at steady state.

\section{Sensitivity Analysis Results}

After ensuring that the reactive distillation process model developed with the aid of Aspen Plus converged under steady state simulation, reflux ratio was varied from 2.0 to 5.5 at a step of 0.5 and the effect of reboiler duty on the mole fraction of methyl oleate given from the bottom section of the column was investigated. The results obtained from the investigations were as shown in Figures 5 to 12 . 


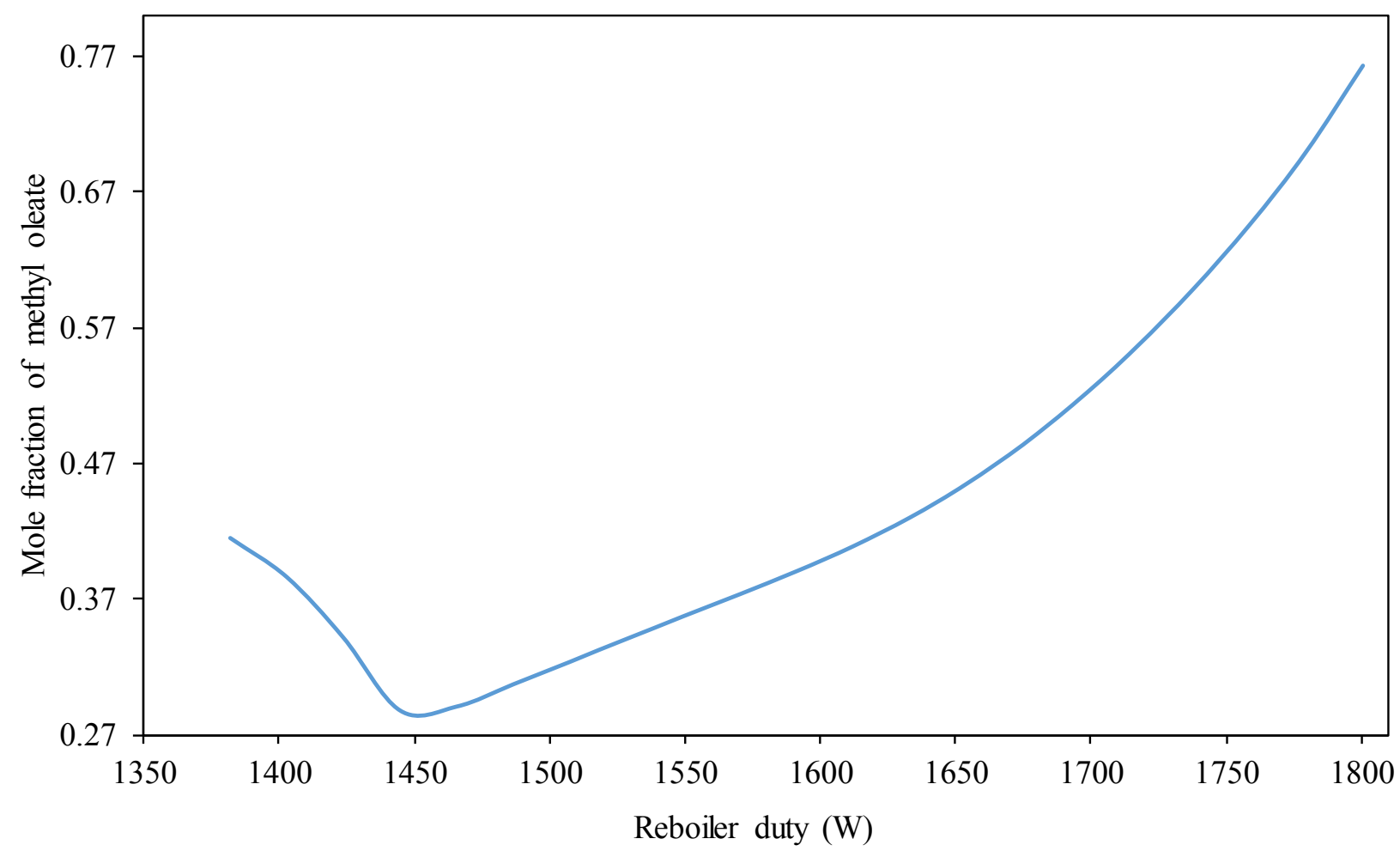

Figure 5. Sensitivity of methyl oleate mole fraction to reboiler duty at $\mathrm{RR}=2.0$

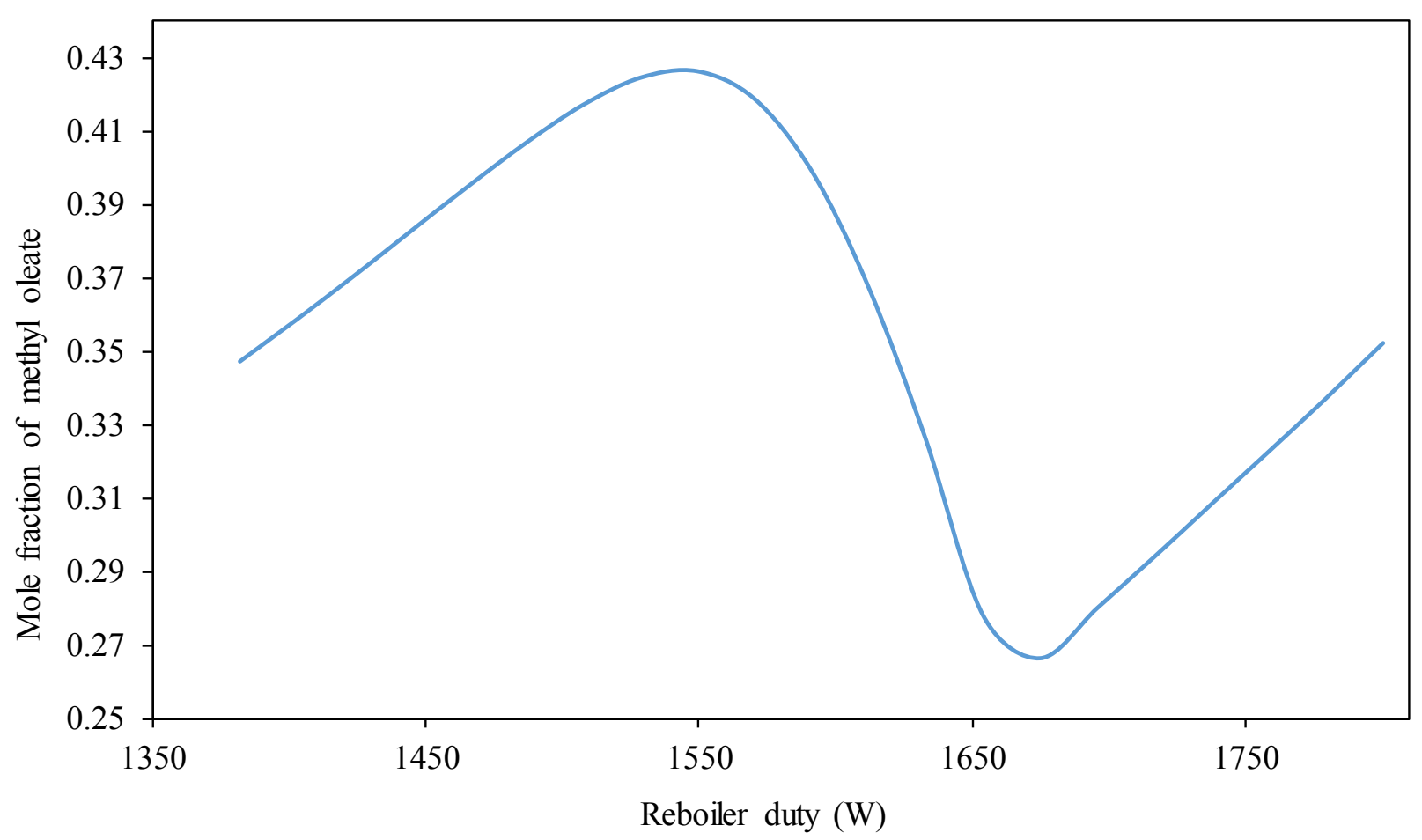

Figure 6. Sensitivity of methyl oleate mole fraction to reboiler duty at $\mathrm{RR}=2.5$

Figure 5 is a plot of mole fraction of methyl oleate against reboiler duty when the reflux ratio was 2. As can be seen from the figure, the process portrayed a uniform reduction in mole fraction when the reboiler duty was less than $1450 \mathrm{~W}$. Afterwards, there was a positive gradient in mole fraction with increase in reboiler duty. Following this increase, a maximum mole fraction of approximately 0.7627 was achieved at a reboiler duty of $1800 \mathrm{~W}$. These were found to be the most favourable conditions of the process within the limits investigated. 


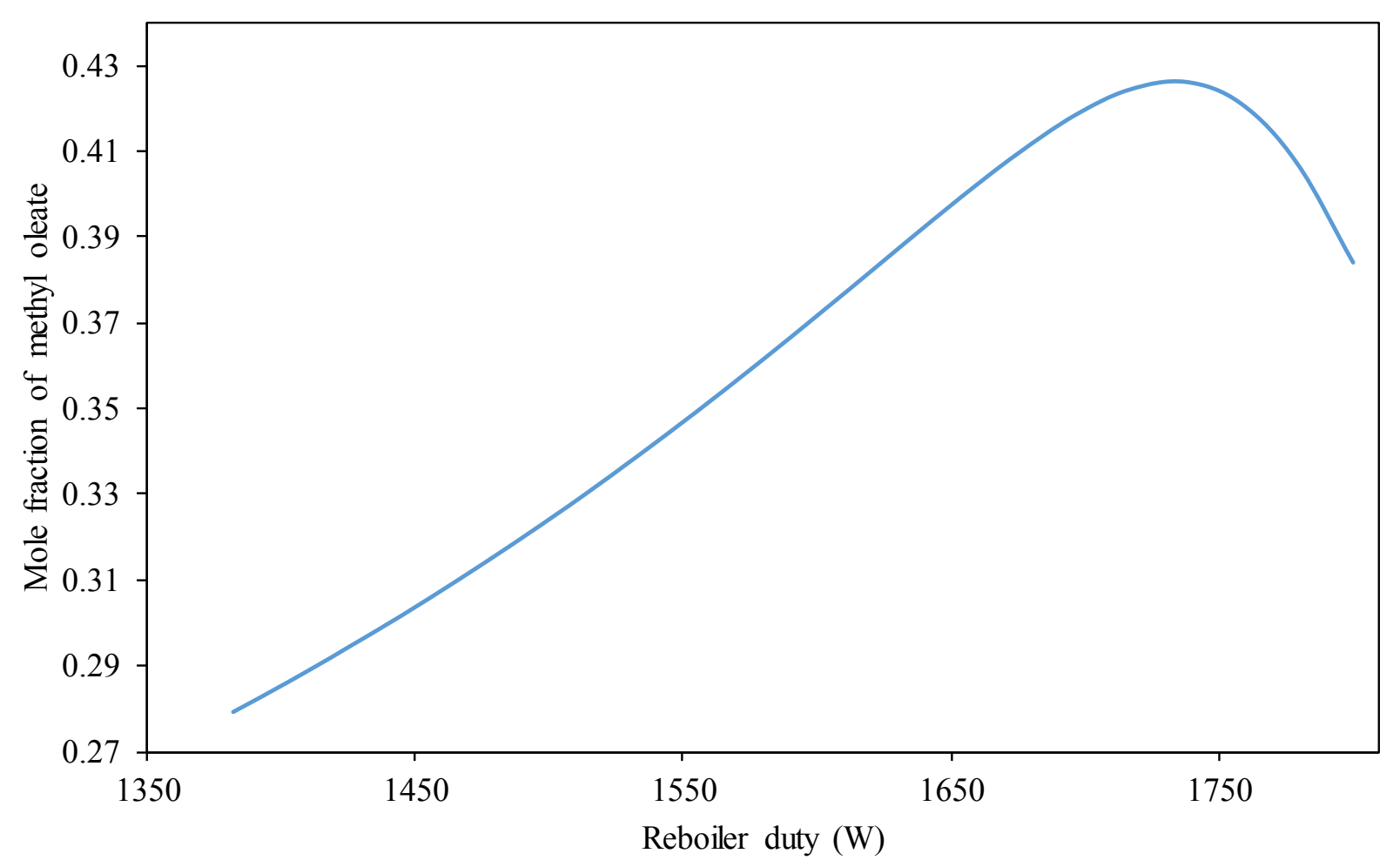

Figure 7. Sensitivity of methyl oleate mole fraction to reboiler duty at $\mathrm{RR}=3.0$

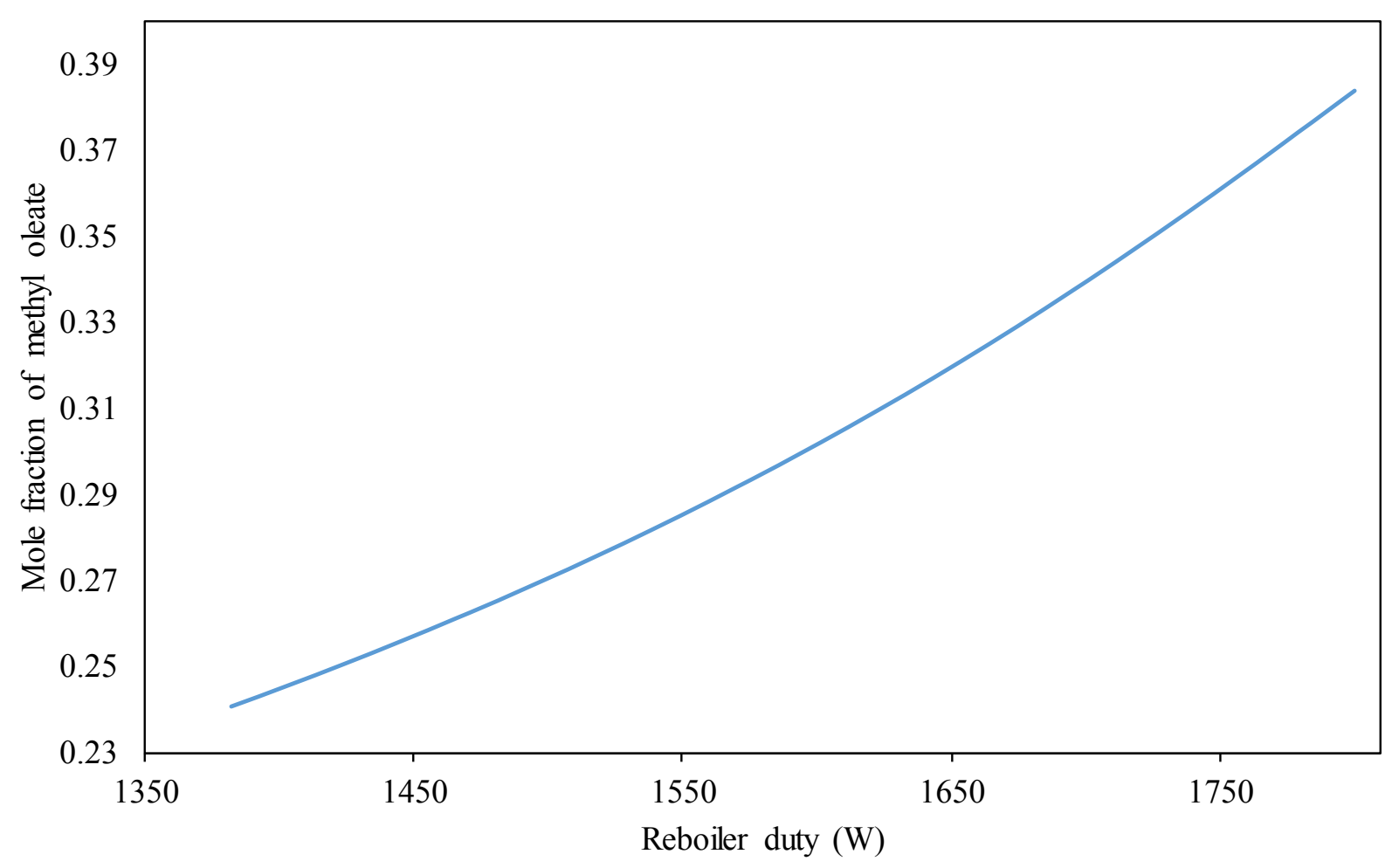

Figure 8 . Sensitivity of methyl oleate mole fraction to reboiler duty at $R R=3.5$

Shown in Figure 6 is a plot of the sensitivity of mole fraction of methyl-oleate to reboiler duty at a reflux ratio of 2.5. The relationship between the mole fraction of methyl oleate and the reboiler was discovered to be similar to that of a slant $N$-shape. In other words, there was an increase, a decline and then another increase at reboiler duties of 1400-1550, 1550-1670 and 1670$1800 \mathrm{~W}$, respectively. This is to say that the mole fraction was fluctuating with increase in the reboiler duty at this reflux ratio. 
Figure 7 is a plot of the results obtained when the sensitivity of mole fraction of methyloleate to reboiler duty at a reflux ratio of 3.0 was investigated. According to the figure, the relationship was found to be more stable in this case than that of a reflux ratio of 2.5. Looking at the figure, it would be noticed that a uniformly increasing mole fraction was obtained up till a reboiler duty of $1750 \mathrm{~W}$ where it then exhibited a decrease. This was found to be an implication that a reboiler duty beyond $1750 \mathrm{~W}$ at a reflux ratio of 3.0 were not favourable conditions for this process.

The plot of the sensitivity of methyl oleate mole fraction towards reboiler duty at a reflux ratio of 3.5 is given in Figure 8. The behaviour of the system at this reflux ratio was found to be quite stable because it produced a uniformly increasing mole fraction within the range of the reboiler duty considered. From the nature of the sensitivity results obtained, it could mean that further increase in reboiler duty at this reflux ratio would yield higher mole fraction of the oleic acid methyl ester (methyl oleate).

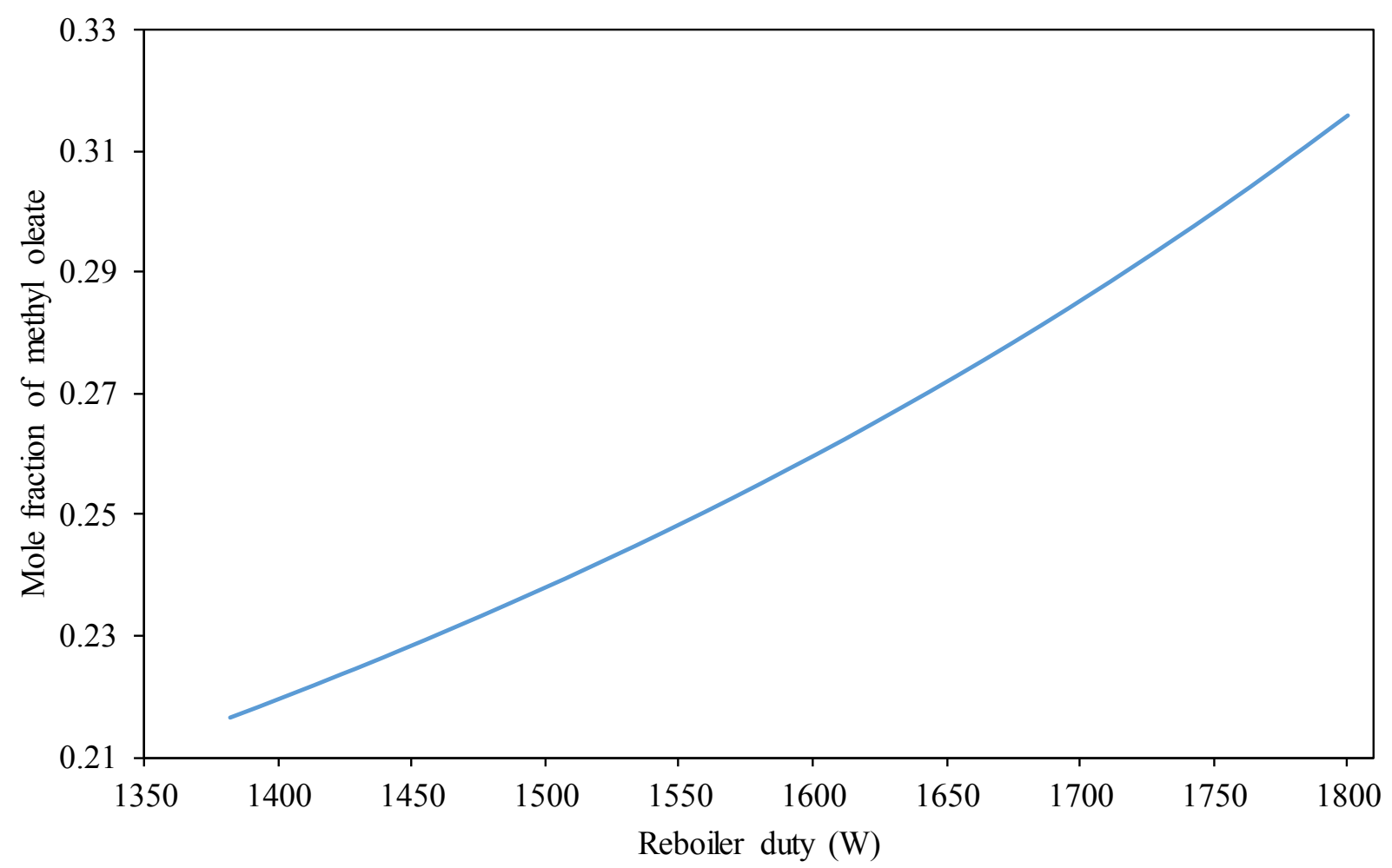

Figure 9. Sensitivity of methyl oleate mole fraction to reboiler duty at $R R=4.0$

Figure 9 shows a plot of the sensitivity of mole fraction of methyl oleate to reboiler duty at a reflux ratio of 4.0. The behaviour of the system towards reboiler duty at this reflux ratio was also found to be very stable because a uniformly increasing mole fraction was observed as the reboiler duty was varied. Actually, the behaviour observed in this case was similar to that given by the system when the reflux ratio was 3.5 and the reboiler duty varied. 


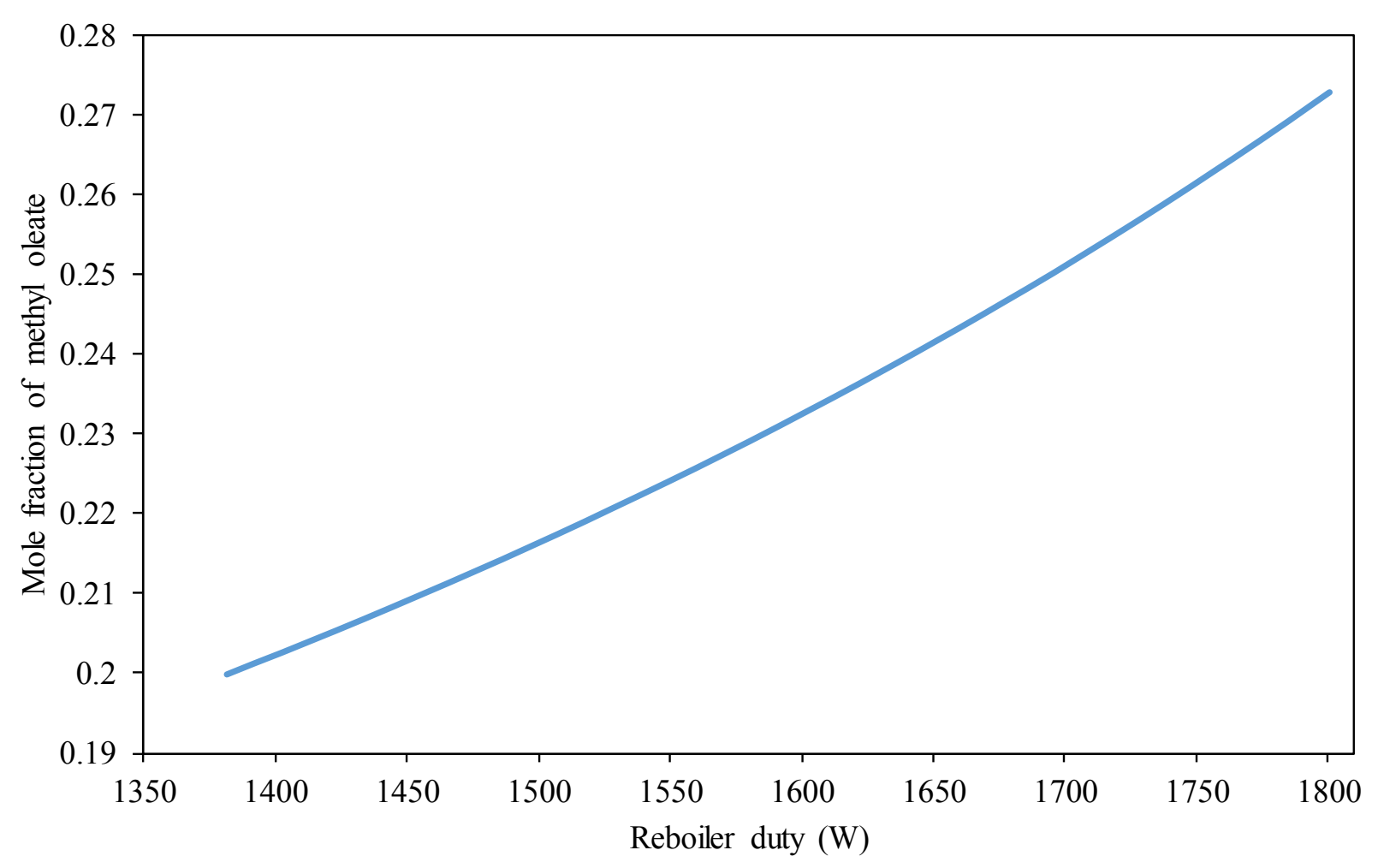

Figure 10. Sensitivity of methyl oleate mole fraction to reboiler duty at $R R=4.5$

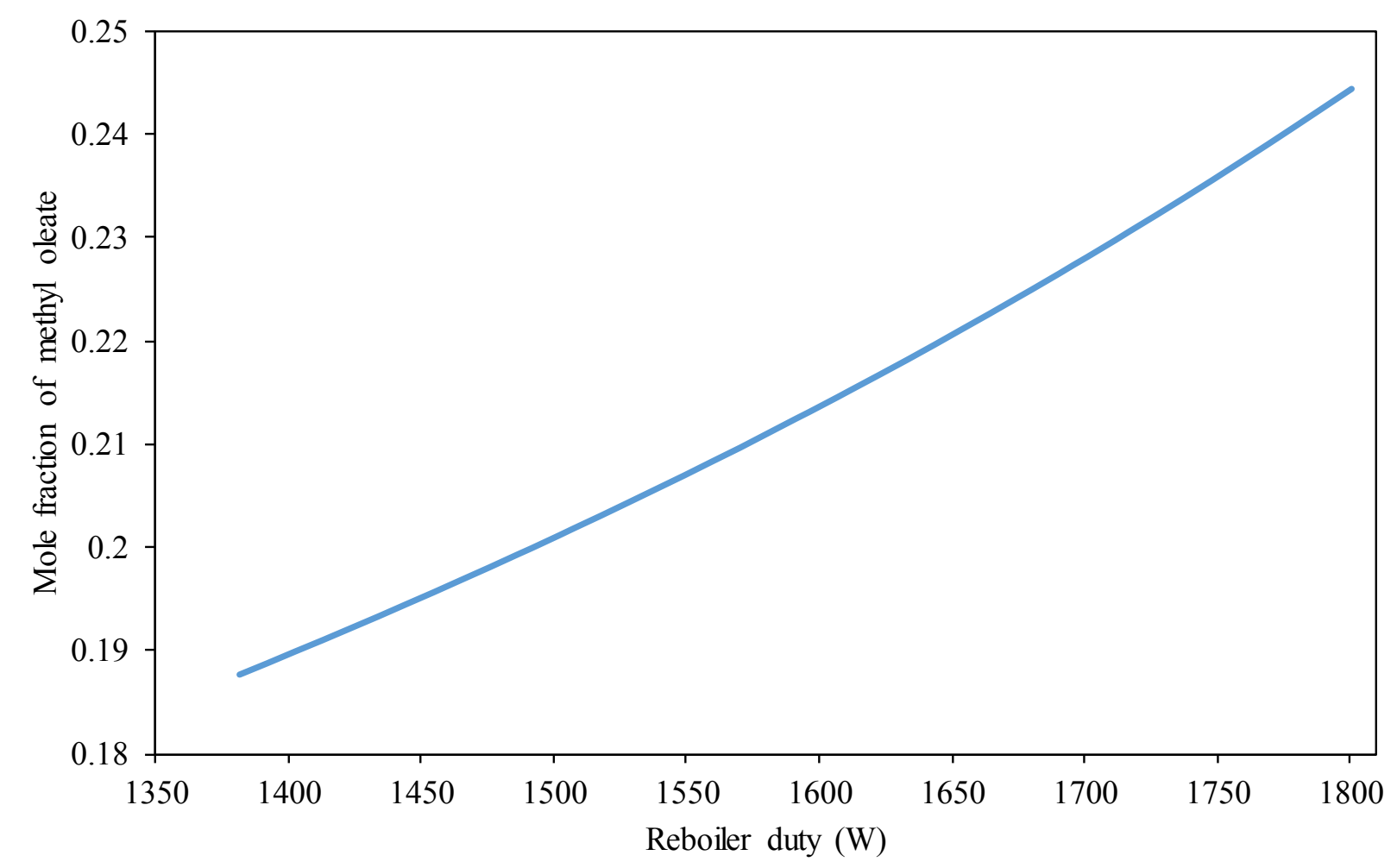

Figure 11. Sensitivity of methyl oleate mole fraction to reboiler duty at $R R=5.0$

In Figures 10, 11 and 12, the plots of the sensitivity of mole fraction of methyl oleate to reboiler duty at constant reflux ratios of 4.0, 4.5 and 5.0 respectively are shown. According to the figures, a uniformly increasing mole fraction profile of methyl oleate was observed in each case, and this is indicating that the behaviour of the system towards the reboiler duty at each different reflux ratio was stable with a positive gradient. 


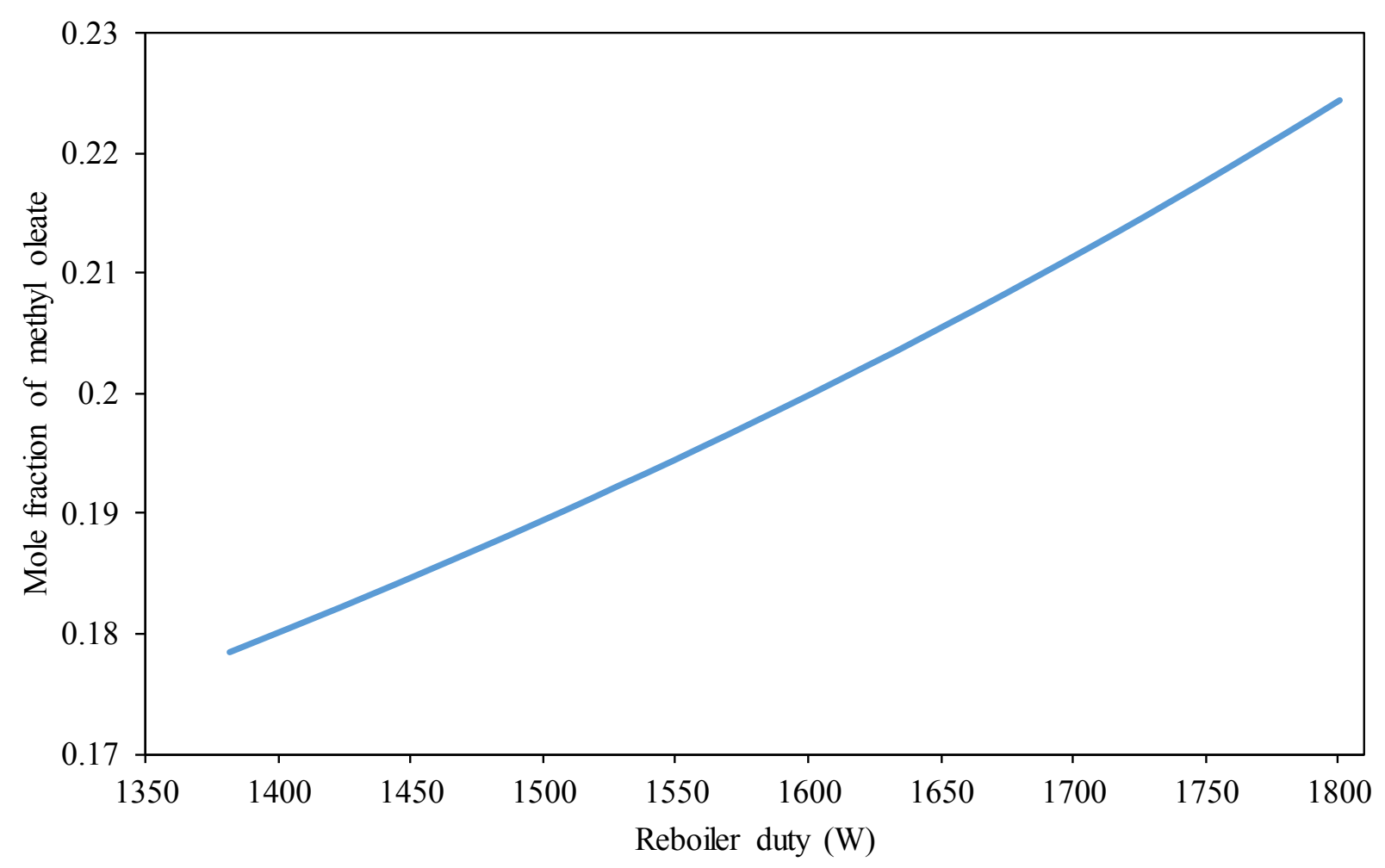

Figure 12. Sensitivity of methyl oleate mole fraction to reboiler duty at $\mathrm{RR}=5.5$

It has, thus, been seen that variation in the reboiler duty of the reactive distillation column at different reflux ratios has resulted in variation in the mole fraction of oleic acid methyl ester (methyl oleate) obtained as the product from the bottom section of the column. In other words, the mole fraction, and by implication, the mass fraction, of the methyl oleate has been observed to be sensitive to both reflux ratio and reboiler duty as the two operating parameters considered in this work.

\section{Conclusion}

The convergence achieved from the steady-state simulation of the reactive distillation process used for the production of oleic acid methyl ester (methyl oleate) indicated that the developed Aspen Plus model of the process was a stable one. Furthermore, from the sensitivity analysis of the process, it was discovered that the mole fraction of the desired product (methyl oleate) was sensitive to both reflux ratio and reboiler duty because the variations in the operating parameters (reflux ratio and reboiler duty) caused corresponding variation in the value of methyl oleate mole fraction given from the bottom section of the column. It has, thus, been discovered that the mole fraction of fatty acid methyl ester obtained from a reactive distillation column is sensitive to both reflux ratio and reboiler duty.

\section{Acknowledgement}

Special thanks go to Aare Afe Babalola, LL.B, FFPA, FNIALS, FCIArb, LL.D, SAN, OFR, CON - The Founder and President, and the Management of Afe Babalola University, Ado-Ekiti, Ekiti State, Nigeria for providing a very conducive environment that enabled the accomplishment of this research work. 


\section{References}

[1] A. Maria, Introduction to modeling and simulation. Proceedings of The 1997 Winter Simulation Conference, (1997) 7-13.

[2] D. Basmadijan, Art of Modeling in Science and Engineering. Boca Raton: Chapman \& Hall CRC, 1999.

[3] C. Ekberg, Sensitivity Analysis and Simulation, Uncertainties in Predictive Geochemical Modeling, 1999.

[4] A.R. Saltelli, Global Sensitivity Analysis: An Introduction, Sensitivity Analysis of Model Output, Los Alamos National Laboratory, 2004.

[5] R.C. Anene, Modelling, Simulation and Sensitivity Analysis of a Fatty Acid Methyl Ester (FAME) Reactive Distillation (RD) Process Using Aspen Plus. An Undergraduate Thesis Submitted to Chemical and Petroleum Engineering Department, College of Engineering, Afe Babalola University, Ado-Ekiti, Ekiti State, Nigeria, 2016.

[6] C. Alexandre, F.O. Dimian, Process for Fatty Acid Methyl Esters by Dual Reactive Distillation. 17th European Symposium On Computer Aided Process Engineering ESCAPE17, (2007) 1-6.

[7] A. Giwa, Steady-State Modeling of n-butyl acetate transesterification process using Aspen PLUS: conventional versus integrated, ARPN Journal of Engineering and Applied Sciences, 7 (2012) 1555-1564.

[8] A. Giwa, Methyl acetate reactive distillation process modeling, simulation and optimization using Aspen Plus. ARPN Journal of Engineering and Applied Sciences, 8 (2013) 386-392.

[9] S.O. Giwa, A. Giwa, H. Hapoglu, Investigating the effects of some parameters on hydrogen sulphide stripping column using Aspen HYSYS, ARPN Journal of Engineering and Applied Sciences, 8 (2013a) 338-347.

[10] A. Giwa, S.O. Giwa, H. Hapoglu, Adaptive neuro-fuzzy inference systems (ANFIS) modeling of reactive distillation process, ARPN Journal of Engineering and Applied Sciences, 8 (2013b) 473-479.

[11] A. Giwa, S. Karacan, Simulation and optimization of ethyl acetate reactive packed distillation process using Aspen Hysys, The Online Journal of Science and Technology, 2 (2012b) 57-63.

[12] A. Giwa, S. Karacan, Nonlinear black-box modeling of a reactive distillation process, International Journal of Engineering Research \& Technology, 1 (2012d) 548-557.

[13] A. Giwa, S. Karacan, Decoupling control of a reactive distillation process using TyreusLuyben Technique, ARPN Journal of Engineering and Applied Sciences, 7 (2012e) 12631272.

[14] A. Giwa, S.O. Giwa, Isopropyl myristate production process optimization using response surface methodology and MATLAB, International Journal of Engineering Research \& Technology, 2 (2013a) 853-862.

[15] A. Giwa, S.O. Giwa, Estimating the optimum operating parameters of olefin metathesis reactive distillation process, ARPN Journal of Engineering and Applied Sciences, 8 (2013b) 614-624.

[16] A. Giwa, S.O. Giwa, İ. Bayram, S. Karacan, Simulations and economic analyses of ethyl acetate productions by conventional and reactive distillation processes using Aspen Plus, International Journal of Engineering Research \& Technology, 2 (2013c) 594-605.

[17] A. Giwa, Solving the dynamic models of reactive packed distillation process using difference formula approaches, ARPN Journal of Engineering and Applied Sciences, 9 (2014) 98-108.

[18] A. Giwa, A. Bello, S.O. Giwa, Performance analyses of fatty acids in reactive distillation process for biodiesel production, International Journal of Scientific \& Engineering Research, 5 (2014) 529-540.

[19] A. Giwa, A. Bello, S.O. Giwa, Artificial neural network modeling of a reactive distillation process for biodiesel production, International Journal of Scientific \& Engineering Research, 6(2015a) 1175- 1191. 
[20] A. Giwa, S.O. Giwa, A.A. Adeyi, Dynamics and servo control of biodiesel purity from a reactive distillation process, International Journal of Scientific \& Engineering Research, 6 (2015) 146-156.

[21] A. Giwa, S.O. Giwa, Modelling and simulation of a reactive distillation process for fuel additive production, Journal of Environmental Science, Computer Science and Engineering \& Technology, Section C: Engineering \& Technology, 5 (2016) 63-74.

[22] A. Giwa, S. Karacan, Modeling and simulation of a reactive packed distillation column using delayed neural networks, Chaotic Modeling and Simulation, 2 (2012a) 101-108.

[23] A. Giwa, S.O. Giwa, Layer-recurrent neural network modelling of reactive distillation process, Chaotic Modeling and Simulation, 2 (2013c) 647-656.

[24] A. Giwa, S. Karacan, Development of dynamic models for a reactive packed distillation column, International Journal of Engineering, 6 (2012c) 118-128.

[25] S. Kumar, Modelling and Simulation of Ethyl Acetate Reactive Distillation Column Using ASPEN PLUS, A Project submitted to the National Institute of Technology, Rourkela, India, 2010.

[26] M. Carrera-Rodríguez, J. G. Segovia-Hernández, A. Bonilla-Petriciolet, Short-cut method for the design of reactive distillation columns, Industrial and Engineering Chemistry Research, 50 (2011) 10730-10743.

[27] M. Agarwal, K. Singh, S.P. Chaurasia, Simulation and sensitivity analysis for biodiesel production in a reactive distillation column, Polish Journal of Chemical Technology, 14 (2012), 59-65.

[28] K.D. Patil, B.D. Kulkarni, Mathematical modeling and simulation of reactive distillation column using MATLAB and Aspen Plus. International Journal of Latest Trends in Engineering, Science and Technology. 1 (2014) 1-8.

[29] S.R. Lone, S.A. Ahmad, Modeling and simulation of ethyl acetate reactive distillation column using Aspen Plus, International Journal of Scientific \& Engineering Research, 3 (2012) 1-5.

[30] S.C. Nwambuonwo, A. Giwa, Modelling, simulation and optimization of fatty acid methyl ester reactive distillation process using Aspen HYSYS. International Journal of Science and Research, 4 (2015) 1218-1224.

[31] D. Datta, D.S. Patle, Sensitivity Analysis of steady-state methyl acetate synthesis reactive distillation column using Aspen Plus, The IUP Journal of Science \& Technology, 6 (2010) 112.

[32] T. Pöpken, S. Steinigeweg, J. Gmehling, Synthesis and Hydrolysis of methyl acetate by reactive distillation using structured catalytic packings: experiments and simulation, Industrial and Engineering Chemistry Research, 40 (2001) 1566-1574.

[33] A. Giwa, S.O. Giwa, Investigating the effects of operating parameters of a reaction integrated distillation process for SAME production using Aspen PLUS. International Journal of Science and Research, 4 (2015) 2349-2356.

[34] A. Giwa, S.O. Giwa, Effects of feed ratio on the product quality of same reactive distillation process, Advances in Applied Science Research, 6 (2015) 135-143.

[35] Aspen, Aspen PLUS V8.4 [30.0.0.33]. Aspen Technology, USA, 2013. 